\title{
VISUAL EVOKED POTENTIALS IN PATIENTS AFTER METHANOL POISONING
}

\section{PAVEL URBAN ${ }^{1,2}$, SERGEY ZAKHAROV ${ }^{2}$, PAVEL DIBLÍK ${ }^{3}$, DANIELA PELCLOVÁ ${ }^{2}$, and PETR RIDZOŇ ${ }^{2}$}

${ }^{1}$ National Institute of Public Health, Prague, Czech Republic

Centre for Industrial Hygiene and Occupational Medicine

${ }^{2}$ Charles University in Prague and General University Hospital in Prague, Prague, Czech Republic

Department of Occupational Medicine, 1st Faculty of Medicine

${ }^{3}$ Charles University in Prague and General University Hospital in Prague, Prague, Czech Republic

Department of Ophthalmology, 1st Faculty of Medicine

\begin{abstract}
Objectives: We report the results of the visual evoked potentials (VEP) examination in patients after severe poisoning by methanol. Material and Methods: The group of 47 patients (38 males and 9 females) was assembled out of persons who survived an outbreak of poisoning by the methanol adulterated alcohol beverages, which happened in the Czech Republic in 2012-2013. The visual evoked potentials examination was performed using monocular checkerboard pattern-reversal stimulation. Two criteria of abnormality were chosen: missing evoked response, and wave P1 latency > 117 ms. Non-parametric statistical methods (median, range, and the median test) were used to analyze factors influencing the VEP abnormality. Results: The visual evoked potential was abnormal in 20 patients (43\%), 5 of them had normal visual acuity on the Snellen chart. The VEP abnormality did not correlate significantly with initial serum concentrations of methanol, formic acid or lactate; however, it showed statistically significant inverse relation to the initial serum $\mathrm{pH}$ : the subgroup with the abnormal VEP had significantly lower median $\mathrm{pH}$ in comparison with the subgroup with the normal VEP $(7.16 \mathrm{vs.} 7.34, \mathrm{p}=0.04)$. The abnormality was not related to chronic alcohol abuse. Conclusions: The visual evoked potentials examination appeared sensitive enough to detected even subclinical impairment of the optic system. Metabolic acidosis is likely to be the key factor related to the development of visual damage induced by methanol. The examination performed with a delay of 1-9 months after the poisoning documented the situation relatively early after the event. It is considered as a baseline for the planned long-term follow-up of the patients, which will make it possible to assess the dynamics of the observed changes, their reversibility, and the occurrence of potential late sequelae.
\end{abstract}

Key words:

Methanol, Poisoning, Visual evoked potentials, VEP, Acidosis, Czech Republic

\section{INTRODUCTION}

The damage to the visual system caused by methanol was first described by MacFarlan in 1855 [1]. Initial clinical symptoms of the damage include photophobia, blurred vision, and scotomata. They may end up in total blindness during a few hours or days. Objective signs include dilated nonreactive pupils, hyperemia of the optic discs and visual field defects. The visual evoked potentials (VEP) examination represents one of the methods that enable to detect and characterize damage to the optic system due

The study was supported by projects of Charles University in Prague No. P25/1LF/2 (project manager: Prof. Jan Škrha, M.D., D.Sc.) and P28/1LF/6 (project manager: Prof. Jana Dušková, M.D., D.Sc.), and EU Project "Material-technical Research Base for the Diagnostics and Treatment of Environmentally-caused and Oncological Disorders and their Risks, at the General University Hospital in Prague", reg. No. CZ.2.16/3.1.00/24.12 (project manager: Prof Jan Malík, M.D., Ph.D.).

Received: September 5, 2014. Accepted: June 24, 2015.

Corresponding author: P. Urban, National Institute of Public Health, Šrobárova 48, 10042 Praha 10, Czech Republic (e-mail: pavel.urban@szu.cz). 
to methanol poisoning. The visual evoked potentials examination is testing the functional integrity of the visual pathway from the retina to the cortical projection areas in the occipital lobe of the brain. The visual evoked potentials are sensitive to detect even a subclinical dysfunction of the generator structures. Moreover, the method is noninvasive and relatively non-demanding from the technical point of view, which makes it suitable for screening purposes and longitudinal monitoring.

We had the opportunity to perform the VEP examination in a group of patients who survived the outbreak of methanol poisoning which happened in the Czech Republic in 2012-2013. Counting 47 patients, our group is the largest one so far published in the literature. Our goal was to describe the pattern of the VEP changes in the patients. The results will serve, among others, as a baseline for the intended long-term follow-up of the group. Clinical and biochemical aspects of the cases as well as the results of other clinical tests were covered by other publications [2,3].

\section{MATERIAL AND METHODS}

In 2012 and 2013, the outbreak of accidental poisonings by methanol happened in the Czech Republic. At least 150 persons were affected after consumption of adulterated alcoholic beverages. By the end of 2013, a total of 48 fatalities were registered. Out of the persons who survived the poisoning, a group of 50 patients was assembled, who underwent comprehensive health status examination. The workup comprised psychological, adictological, ophthalmological, and neurological tests, including the magnetic resonance imaging (MRI) and the VEP examination [4,5].

The visual evoked potentials examination was done for 47 patients (38 males and 9 females) who survived methanol poisoning. The examination was performed within 1-9 months after the acute event. Monocular checkerboard pattern-reversal stimulation was used, with stimulation frequency of $1.5 \mathrm{c} / \mathrm{s}$, angular size of the monitor $6^{\circ} \times 5^{\circ}$ from the fixation point, angular size of checkerboard squares $40^{\prime}$. Luminance of the white and black squares was $84 \mathrm{~cd} / \mathrm{m}^{2}$ and $57 \mathrm{~cd} / \mathrm{m}^{2}$, respectively. Bandwidth of the amplifier was $1 \mathrm{~Hz}-1 \mathrm{kHz}$, The evoked response was registered from the $\mathrm{Oz}-\mathrm{Fz}$ derivation. Two hundred epochs were averaged. Each eye was examined twice in order to check reproducibility of the evoked complex. We evaluated latencies of waves N1, P1, and N2, and amplitudes N1P1 and P1N2. The values measured for patients were compared with our laboratory reference values determined as the central $95 \%$ interquartile interval of data measured for a group of 30 healthy individuals. Two criteria of abnormality were chosen: non-elicitable evoked response and wave P1 latency above the upper limit of our laboratory norm, i.e. $117 \mathrm{~ms}$. The result of the examination of a patient was categorized as abnormal if at least 1 of the above-mentioned criteria was fulfilled at least for 1 eye.

Using the Kolmogorov-Smirnov Goodness-of-Fit Test to test normality, we found that the distribution of many quantitative parameters significantly differed from the normal Gaussian distribution. Therefore, we chose non-parametric methods for the statistical analysis, namely the median and the range as descriptive statistics, and the median test to perform comparisons of the medians of various quantitative parameters in 2 independent groups. The level of statistical significance was set at $p \leq 0.05$.

\section{RESULTS}

The Table 1 gives demographic characteristics of the patients and some measures of methanol poisoning severity as they were recorded at the initial admission to hospital, save for carbohydrate deficient transferring (CDT) level, as a marker of long-term alcohol abuse, which was determined on the day of the VEP examination. The differences between males and females did not reach statistical significance for any of the parameters. 
Table 1. Demographic characteristics of the patients and values of methanol poisoning severity parameters

\begin{tabular}{|c|c|c|c|c|c|c|c|}
\hline \multirow{3}{*}{ Variable } & \multicolumn{6}{|c|}{ Patients } & \multirow{3}{*}{$\begin{array}{c}\text { Statistical } \\
\text { - significance } \\
\text { of difference } \\
-\quad \text { (median } \\
\text { test) }\end{array}$} \\
\hline & \multicolumn{2}{|c|}{$\begin{array}{c}\text { total } \\
(\mathrm{N}=47)\end{array}$} & \multicolumn{2}{|c|}{$\begin{array}{c}\text { males } \\
(\mathrm{N}=38)\end{array}$} & \multicolumn{2}{|r|}{$\begin{array}{l}\text { females } \\
(\mathrm{N}=9)\end{array}$} & \\
\hline & $\mathrm{Me}$ & range & $\mathrm{Me}$ & range & $\mathrm{Me}$ & range & \\
\hline Age [years] & 48.00 & $23.00-73.00$ & 46.00 & $25.00-73.00$ & 52.00 & $23.00-66.00$ & n.s. \\
\hline $\mathrm{CDT}[\mathrm{mg} \%]$ & 1.45 & $0.70-17.60$ & 1.50 & $0.70-17.60$ & 1.20 & $1.00-3.10$ & n.s. \\
\hline Methanol in serum $[\mathrm{mg} / \mathrm{l}]$ & 863.00 & $85.00-7307.00$ & 793.00 & $85.00-7307.00$ & 1090.00 & $87.00-5313.00$ & n.s. \\
\hline Formic acid in serum $[\mathrm{mg} / \mathrm{l}]$ & 650.00 & $13.00-1040.00$ & 546.00 & $13.00-1400.00$ & 683.00 & $509.00-765.00$ & n.s. \\
\hline Lactate in serum $[\mathrm{mmol} / \mathrm{l}]$ & 1.90 & $0.70-17.10$ & 1.90 & $0.70-17.10$ & 2.00 & $0.90-6.40$ & n.s. \\
\hline $\mathrm{pH}$ in serum & 7.25 & $6.69-7.46$ & 7.29 & $6.69-7.46$ & 7.14 & $7.06-7.42$ & n.s. \\
\hline
\end{tabular}

CDT - carbohydrate deficient transferring; Me - median; n.s. - non-significant.

Results of the VEP examination were evaluated as normal for 27 patients (57\%), and as abnormal for 20 patients (43\%), as shown in the Table 2. The abnormal results were relatively more frequent in males $(45 \%)$ than in females $(33 \%)$; however, the difference did not reach statistical significance. Abnormality consisted in unelicitable evoked response in 3 cases, and in latency prolongation in 17 cases, which was combined with the decrease in amplitude in 6 cases. The values of prolonged latency were mostly between $118 \mathrm{~ms}$ and $130 \mathrm{~ms}$. The highest observed value was $154 \mathrm{~ms}$.

In the Table 3, patients were divided into 2 subgroups on the basis of the VEP results. The subgroup of patients with the normal VEP was then compared with the subgroup of patients with the abnormal VEP by means of some indices of the clinical severity of the poisoning,

Table 2. Results of visual evoked potential (VEP) examination in individual patients

\begin{tabular}{|c|c|c|c|c|c|c|c|c|c|c|c|c|}
\hline & & & & ight e & & & & & eft ey & & & \\
\hline & ient & & $\begin{array}{c}\text { latency } \\
\text { [ms] }\end{array}$ & & & & & $\begin{array}{l}\text { latency } \\
{[\mathrm{ms}]}\end{array}$ & & amp & ude & Result \\
\hline No. & ID & $\mathrm{N} 1$ & $\mathrm{P} 1$ & $\mathrm{~N} 2$ & N1P1 & P1N2 & $\mathrm{N} 1$ & $\mathrm{P} 1$ & $\mathrm{~N} 2$ & N1P1 & P1N2 & \\
\hline 1 & B.P. & n.e. & n.e. & n.e. & n.e. & n.e. & 99 & 118 & 145 & 4.9 & 7.6 & abnormal \\
\hline 2 & B.K. & 96 & 114 & 136 & 4.1 & 6.9 & 90 & 113 & 137 & 4.9 & 6.0 & normal \\
\hline 3 & B.J. & 98 & 116 & 150 & 3.7 & 7.7 & 99 & 117 & 150 & 4.3 & 9.8 & normal \\
\hline 4 & B.L. & 92 & 113 & 150 & 13.3 & 24.0 & 87 & 109 & 150 & 11.6 & 21.9 & normal \\
\hline 5 & C.J. & 84 & 104 & 139 & 7.2 & 8.2 & 85 & 106 & 138 & 7.0 & 7.4 & normal \\
\hline 6 & C.D. & 93 & 117 & 145 & 10.4 & 12.8 & 86 & 117 & 143 & 11.5 & 12.0 & normal \\
\hline 7 & D.J. & 97 & 109 & 145 & 1.5 & 2.2 & 104 & 137 & 163 & 1.5 & 1.5 & abnormal \\
\hline 8 & F.L. & 89 & 109 & 141 & 7.7 & 16.2 & 86 & 109 & 142 & 9.3 & 18.5 & normal \\
\hline 9 & H.M. & 104 & 120 & 144 & 2.8 & 4.5 & 100 & 119 & 138 & 2.1 & 3.3 & abnormal \\
\hline 10 & J.J. & 105 & 122 & 152 & 2.4 & 2.7 & 104 & 123 & 150 & 5.1 & 3.6 & abnormal \\
\hline 11 & J.P. & 90 & 110 & 137 & 7.1 & 12.9 & 87 & 106 & 133 & 9.9 & 12.4 & normal \\
\hline 12 & K.R. & 91 & 116 & 135 & 5.1 & 4.4 & 92 & 117 & 134 & 4.1 & 3.8 & normal \\
\hline
\end{tabular}


Table 2. Results of visual evoked potential (VEP) examination in individual patients - cont.

\begin{tabular}{|c|c|c|c|c|c|c|c|c|c|c|c|c|}
\hline & & \multicolumn{5}{|c|}{ Right eye } & \multicolumn{5}{|c|}{ Left eye } & \multirow{3}{*}{ Result } \\
\hline \multicolumn{2}{|c|}{ Patient } & \multicolumn{3}{|c|}{$\begin{array}{c}\text { latency } \\
{[\mathrm{ms}]}\end{array}$} & \multicolumn{2}{|c|}{$\begin{array}{c}\text { amplitude } \\
{[\mu \mathrm{V}]}\end{array}$} & \multicolumn{3}{|c|}{$\begin{array}{c}\text { latency } \\
{[\mathrm{ms}]}\end{array}$} & \multicolumn{2}{|c|}{$\begin{array}{l}\text { amplitude } \\
{[\mu \mathrm{V}]}\end{array}$} & \\
\hline No. & ID & $\mathrm{N} 1$ & $\mathrm{P} 1$ & $\mathrm{~N} 2$ & N1P1 & P1N2 & $\mathrm{N} 1$ & $\mathrm{P} 1$ & $\mathrm{~N} 2$ & N1P1 & $\mathrm{P} 1 \mathrm{~N} 2$ & \\
\hline 13 & K.I. & 79 & 96 & 125 & 2.0 & 1.7 & 76 & 93 & 122 & 2.0 & 3.0 & normal \\
\hline 14 & K.A. & 88 & 112 & 143 & 7.5 & 9.0 & 88 & 114 & 144 & 7.2 & 9.3 & normal \\
\hline 15 & L.E. & 91 & 126 & 149 & 4.7 & 7.4 & 97 & 123 & 149 & 6.8 & 8.4 & abnormal \\
\hline 16 & L.J. & 85 & 107 & 132 & 8.4 & 7.0 & 86 & 108 & 132 & 9.6 & 7.3 & normal \\
\hline 17 & L.V. & 95 & 123 & 152 & 3.3 & 7.0 & 94 & 120 & 149 & 41.0 & 5.5 & abnormal \\
\hline 18 & L.I. & 90 & 108 & 134 & 3.8 & 7.2 & 93 & 109 & 139 & 3.2 & 6.7 & normal \\
\hline 19 & M.M. & 93 & 113 & 143 & 5.1 & 9.0 & 94 & 112 & 135 & 7.2 & 9.1 & normal \\
\hline 20 & M.P. & 97 & 116 & 140 & 5.5 & 15.1 & 100 & 117 & 146 & 6.2 & 17.1 & normal \\
\hline 21 & M.Z. & 97 & 125 & 146 & 2.4 & 2.4 & 104 & 128 & 149 & 2.7 & 2.8 & abnormal \\
\hline 22 & M.J. & 94 & 117 & 152 & 5.9 & 8.2 & 93 & 116 & 152 & 8.2 & 8.9 & normal \\
\hline 23 & P.P. & 90 & 122 & 157 & 8.2 & 15.2 & 95 & 122 & 152 & 8.1 & 14.1 & abnormal \\
\hline 24 & P.R. & 100 & 121 & 147 & 3.1 & 5.3 & 94 & 116 & 145 & 5.7 & 5.5 & abnormal \\
\hline 25 & P.J. & 104 & 136 & 168 & 4.6 & 8.5 & 103 & 140 & 176 & 3.6 & 7.5 & abnormal \\
\hline 26 & R.J. & 94 & 120 & 160 & 6.9 & 5.0 & 94 & 122 & 158 & 7.6 & 4.0 & abnormal \\
\hline 27 & R.F. & b.e. & b.e. & b.e. & b.e. & b.e. & b.e. & b.e. & b.e. & b.e. & b.e. & abnormal \\
\hline 28 & S.S. & 85 & 107 & 126 & 15.1 & 8.2 & 84 & 107 & 129 & 14.1 & 9.7 & normal \\
\hline 29 & S.T. & 98 & 120 & 162 & 0.4 & 1.7 & 118 & 134 & 167 & 1.44 & 2.0 & abnormal \\
\hline 30 & S.K. & b.e. & b.e. & b.e. & b.e. & b.e. & 119 & 154 & 184 & 1.9 & 2.7 & abnormal \\
\hline 31 & S.P. & 91 & 114 & 137 & 6.1 & 6.6 & 89 & 115 & 143 & 6.9 & 7.5 & normal \\
\hline 32 & S.J. & o.p. & o.p. & o.p. & o.p. & o.p. & 95 & 116 & 138 & 5.3 & 9.7 & normal \\
\hline 33 & T.P. & 89 & 112 & 137 & 13.4 & 14.3 & 91 & 111 & 139 & 10.5 & 11.6 & normal \\
\hline 34 & T.A. & 85 & 109 & 141 & 16.6 & 22.3 & 85 & 110 & 140 & 14.3 & 18.9 & normal \\
\hline 35 & T.J. & 93 & 120 & 147 & 1.8 & 1.5 & 93 & 124 & 154 & 2.1 & 2.8 & abnormal \\
\hline 36 & T.D. & b.e. & b.e. & b.e. & b.e. & b.e. & b.e. & b.e. & b.e. & b.e. & b.e. & abnormal \\
\hline 37 & V.A. & 94 & 123 & 153 & 7.9 & 12.3 & 91 & 118 & 150 & 10.1 & 15.8 & abnormal \\
\hline 38 & V.S. & 85 & 114 & 139 & 9.6 & 9.4 & 87 & 113 & 135 & 11.3 & 9.3 & normal \\
\hline 39 & V.J. & 93 & 112 & 142 & 5.7 & 5.9 & 94 & 111 & 143 & 6.1 & 5.4 & normal \\
\hline 40 & V.M. & 91 & 114 & 150 & 6.1 & 8.9 & 109 & 136 & 159 & 4.0 & 4.6 & abnormal \\
\hline 41 & V.A. & 98 & 123 & 159 & 5.6 & 10.2 & 105 & 124 & 167 & 3.6 & 4.2 & abnormal \\
\hline 42 & V.V. & 104 & 121 & 141 & 5.0 & 7.2 & 98 & 120 & 141 & 6.1 & 8.8 & abnormal \\
\hline 43 & V.I. & 87 & 111 & 145 & 7.6 & 11.6 & 89 & 110 & 139 & 6.6 & 7.3 & normal \\
\hline 44 & V.S. & 92 & 114 & 134 & 8.8 & 7.9 & 91 & 111 & 133 & 8.4 & 7.2 & normal \\
\hline 45 & V.M. & 89 & 108 & 127 & 7.7 & 7.3 & 86 & 108 & 127 & 9.4 & 7.1 & normal \\
\hline 46 & V.Z. & 96 & 113 & 145 & 6.3 & 8.4 & 95 & 112 & 143 & 5.7 & 6.5 & normal \\
\hline 47 & W.P. & 89 & 114 & 143 & 5.6 & 9.5 & 90 & 111 & 145 & 4.9 & 9.9 & normal \\
\hline
\end{tabular}

n.e. - not examined for technical reasons; b.e. - blind eye; o.p. - ocular prosthesis. 
Table 3. Comparison of the methanol poisoning severity parameters in the subgroups of patients with normal and abnormal visual evoked potentials (VEP)

\begin{tabular}{|c|c|c|c|c|c|}
\hline \multirow{3}{*}{ Variable } & \multicolumn{4}{|c|}{ VEP } & \multirow{3}{*}{$\begin{array}{c}\text { Statistical } \\
\text { significance } \\
\text { of the difference } \\
\text { (median test) }\end{array}$} \\
\hline & \multicolumn{2}{|c|}{$\begin{array}{c}\text { normal } \\
(\mathrm{N}=27)\end{array}$} & \multicolumn{2}{|c|}{$\begin{array}{l}\text { abnormal } \\
(\mathrm{N}=20)\end{array}$} & \\
\hline & $\mathrm{Me}$ & range & $\mathrm{Me}$ & range & \\
\hline Methanol in serum [mg/l] & 705.00 & $85.00-3000.00$ & 1165.00 & $170.00-7307.00$ & n.s. \\
\hline Formic acid in serum $[\mathrm{mg} / \mathrm{l}]$ & 511.00 & $13.00-1400.00$ & 693.00 & $43.00-1012.00$ & n.s. \\
\hline Lactate in serum $[\mathrm{mmol} / \mathrm{l}]$ & 1.90 & $0.70-17.10$ & 2.10 & $0.90-16.30$ & n.s. \\
\hline $\mathrm{pH}$ in serum & 7.34 & $6.98-7.46$ & 7.16 & $6.69-7.44$ & $p=0.04$ \\
\hline Ethanol in serum $[\mathrm{mg} / \mathrm{l}]$ & 45.00 & $0.00-1310.00$ & 50.00 & $0.00-4460.00$ & n.s. \\
\hline $\mathrm{CDT}$ in serum $[\mathrm{mg} \%]$ & 1.85 & $0.80-16.60$ & 1.35 & $0.70-17.60$ & n.s. \\
\hline
\end{tabular}

Abbreviations as in Table 1.

namely the initial serum concentration of methanol, formic acid, lactate and $\mathrm{pH}$. As it may be seen, the subgroup with the abnormal VEP showed significantly lower median $\mathrm{pH}$ as compared to the subgroup with the normal VEP (7.16 vs. 7.34, $p=0.04$ ). Although the medians of methanol, formic acid and lactate concentrations were higher in the subgroup with the abnormal VEP as compared to the subgroup with the normal VEP, none of the differences reached statistical significance. Carbohydrate deficient transferring blood level, as an indicator of chronic alcohol abuse, did not differ between the two groups.

\section{DISCUSSION}

In our group of 47 patients after methanol poisoning we found the abnormal VEP, as an electrophysiological marker of damage to the visual system, in the case of 20 subjects (43\%). Five of them showed normal visual acuity at examination on the Snellen chart. It means that the VEP examination detected subclinical visual damage in these patients. This demonstrated high sensitivity of the VEP examination. There was no statistical difference in frequency of the abnormal VEP between men and women.

In 3 cases, the evoked response could not be elicited because of total blindness. In the other 17 cases, the abnormality consisted in latency prolongation, which was combined with the decrease in the amplitude in 6 cases. As it is known, wave latency is associated with conduction velocity of nerve fibers, and this is related to the status of the myelin sheaths. Therefore, we suppose that functional and/or structural damage to the myelin sheaths may underlie the pathophysiological mechanism of the observed VEP abnormality in our patients.

This assumption is supported by findings by Sharpe (1982) who described morphological changes in the optic nerves in 4 fatal cases of methanol poisoning [6]. He observed demyelination of the retrolaminar part of the optic nerves and preservation of axons. Of course, in cases with significant reduction of the VEP amplitude, we suppose the combination of demyelination and axonal lesion. In our patients, the VEP was examined not sooner than 4 weeks after the event. This time is long enough for the receding of the acute manifestations of the poisoning, such as pseudopapillitis or acute optic neuritis. Therefore, we suppose that our findings reflect rather the long-term visual sequelae of the poisoning.

Further, we searched for any possible association between the abnormal VEP and some laboratory parameters of clinical severity of methanol poisoning measured at the initial admission to a hospital. It was only the inverse association 
between the serum $\mathrm{pH}$ and the VEP abnormality that reached statistical significance $(p=0.04)$. Therefore, it seems that the key factor related to the development of the VEP abnormality is the metabolic acidosis induced by methanol metabolism. On the contrary, since the occurrence of the VEP abnormality did not correlate with the CDT level determined on the day of the VEP examination, we suppose that the VEP changes were not linked to the chronic alcohol abuse.

In our group, both genders were represented, with the prevalence of males (38 vs. 9), which was described in methanol poisoning outbreaks also in other countries, e.g., in Estonia or in Norway [7,8]. There were differences between males and females both in parameters describing severity of the poisoning (Table 3) and in the frequency of the VEP abnormality. The median values of the serum methanol, formic acid, and lactate concentrations at admission were higher for females than for males, and the median $\mathrm{pH}$ value in serum was lower for females than for males.

However, despite the fact that the median values of the indicators of the poisoning severity were more serious for females than for males, the frequency of the VEP abnormality was higher for males than for females (45\% vs. $33 \%$ ). So the gender differences were inconsistent. Moreover, none of the differences reached statistical significance. Therefore, we consider them just as chance variations. Neither the gender differences in the treatment outcomes or the health sequelae of the poisoning, which we analyzed in another study, showed statistical significance [9].

The above described differences between males and females might be related to the gender differences in alcohol consumption patterns. Typically, females got poisoned during sporadic, out of the ordinary drinking of a few "glasses." In contrast, males were commonly used to consuming alcoholic beverages for longer periods, sometimes for several consecutive days ("binge drinking"), which may have resulted in an increased tolerance to ethanol. Importantly, at least $1 / 3$ of males in our study co-ingested other alcoholic beverages that were not adulterated by methanol (wine, beer) whereas only one female did so. The ensuing competitive inhibition of alcohol dehydrogenase enzyme (ADH-enzyme) by ethanol had protective effect against methanol poisoning.

The visual evoked potentials changes, similar to those we have observed in humans, were described in animal experiments on rats using stimulation by flash $[10,11]$. There are also sporadic case reports on the VEP changes in humans after methanol poisoning. McKellar [12] described the decreased VEP amplitude and normal latency for 2 patients with methanol poisoning. Hantson [13] examined the VEP for 19 patients with methanol poisoning within $48 \mathrm{~h}$ after hospital admission. He found the abnormal VEP for 14 of them. The abnormality correlated with the $\mathrm{pH}$ and serum concentration of the formic acid. In the case of the patient described by Essama-Mbia [14] the VEP abnormality was detected on the 1st day, and the patient recovered on the control examination on the 8th day under fomepizol treatment. Brahmi [15] examined the VEP for 7 patients after the outbreak of methanol poisonings in Tunisia in 2003-2004. The abnormal VEP was found in the case of 2 of them. In the case described by Gupta [16], an asymmetrical wave P1 latency prolongation was observed. Thus, our findings are in agreement with those described in the literature. In comparison with the above cited human data, our group is unique in terms of its size, detailed characterization of clinical parameters of poisoning severity and thorough analysis of the VEP results.

Since the observed VEP changes probably mainly reflect demyelination and may be functional in character, they are likely to be at least partly reversible. The speculation is supported by some data in the literature. Scrimgeour [17] described a patient who developed complete blindness on both eyes having drunk about $100 \mathrm{ml}$ of 
methanol. After 1 year, visual acuity on 1 eye improved to $6 / 12$, and on the other eye he was able to detect finger movements. Hantson [13] also described improvement for 4 out of 14 cases of optic neuropathy due to methanol poisoning. By contrast, 8 out of 22 patients from the group of persons with methanol poisoning during the outbreak in Estonia in 2001, who did not have visual problems at the onset, developed late visual problems in the course of the 6 years of the follow-up [18].

The fact that the visual damage constitutes one of the most striking and regular components of the clinical picture of methanol poisoning is noteworthy. The optic nerve is known to be highly sensitive to impairment of adenosine triphosphate (ATP) production. The sensitivity is related to the fact that axons of the optic nerve are relatively long and their diameter is small, which makes mitochondrial transport difficult [19]. Especially the prelaminar, nonmyelinated segment of the optic nerve with high concentration of mitochondria may be considered to be fragile "chokepoint" [20].

The retina is among the most demanding body tissues in terms of the relative oxygen consumption. In this aspect it is even more demanding than the brain is [21]. Moreover, the eye selectively accumulates the formic acid derived from methanol because the oxidation of the formate in the eye is slower than it is in the brain. It was found that the concentration of formic acid in the vitreous humor and in the retina may be higher by $50 \%$ than in the retrolaminar segment of the optic nerve and in the brain [22]. Formic acid inhibits cytochrome oxidase c. The inhibition leads to the impairment of oxidative phosphorylation, to the disruption of the ATP production and to an energetic crisis in the cell. The structural elements of the retina showing earliest signs of damage are the Müller glial cells. In agreement with this, the decrease in the amplitude of the ERG wave b, which is generated by those cells, was observed [10,11]. The harmful effect of methanol is probably primarily retinotoxic.

\section{CONCLUSIONS}

The visual evoked potentials examination proved to be a highly sensitive marker of toxic damage to the optic system due to methanol, even if the impairment was subclinical. The examination is suitable for long-term follow up of the affected patients.

\section{ACKNOWLEDGMENTS}

The authors thank Dr. Bohumír Procházka, Ph.D., for statistical analysis of the data, and Dr. Pavel Chýle, Ph.D., for linguistic assistance.

\section{REFERENCES}

1. MacFarlan JF. On methylated spirits and some of its preparations. Pharm J Trans. 1855;15:310-5. Cited according to [11].

2. Zakharov S, Pelclova D, Navratil T, Belacek J, Kurcova I, Komzak O, et al. Intermittent hemodialysis vs. continuous hemodialysis/hemodiafiltration to eliminate methanol and formate during treatment for methanol poisoning. Kidney Int. 2014;86(1):199-207, http://dx.doi.org/10.1038/ki.2014.60.

3. Zakharov S, Nurieva O, Navrátil T, Diblík P, Kuthan P, Pelclová D. Acute methanol poisonings: Folates administration and visual sequelae. J Appl Biomed. 2014;12(4):309-16, http://dx.doi.org/10.1016/j.jab.2014.04.001.

4. Vaneckova M, Zakharov S, Klempir J, Ruzicka E, Bezdicek O, Liskova I, et al. Methanol intoxication on magnetic resonance imaging. Cesk Slov Neurol Neurochir. 2014;77/110(2):235-9.

5. Bezdicek O, Klempir J, Liskova I, Michalec J, Vaneckova M, Seidl Z, et al. Sequelae of methanol poisoning for cognition. Cesk Slov Neurol Neurochir. 2014;77/110(3):320-5.

6. Sharpe JA, Hostovsky M, Bilbao JM, Rewcastle NB. Methanol optic neuropathy: A histopathological study. Neurology. 1982;32(10):1093-100, http://dx.doi.org/10.1212/WNL. 32.10.1093.

7. Paasma R, Hovda KE, Tikkerberi A, Jacobsen D. Methanol mass poisoning in Estonia: Outbreak in 154 patients. Clin Toxicol. 2007;45:152-7, http://dx.doi.org/10.1080/15563 650600956329. 
8. Hovda KE, Hunderi OH, Tafjord AB, Dunlop O, Rudberg N, Jacobsen D. Methanol outbreak in Norway 20022004: Epidemiology, clinical features and prognostic signs. J Intern Med. 2005;258:181-90, http://dx.doi.org/10.1111/ j.1365-2796.2005.01521.x.

9. Zakharov S, Pelclova D, Urban P, Navratil T, Diblik P, Kuthan P, et al. Czech mass methanol outbreak 2012: Epidemiology, challenges and clinical features. Clin Toxicol. 2014;52(10):1013-24, http://dx.doi.org/10.3109/15563650.20 14.974106.

10. Eells JT. Methanol-induced visual toxicity in the rat. J Pharmacol Exp Ther. 1991;257(1):56-63.

11. Lee WE, Garner CD, Terzo TS. A rat model manifesting methanol-induced visual dysfunction suitable for both acute and long-term exposure studies. Toxicol Appl Pharmacol. 1994;128:199-206, http://dx.doi.org/10.1006/taap.1994.1198.

12. McKellar MJ, Hidajat RR, Elder MJ. Acute ocular methanol toxicity: Clinical and electrophysiological features. Aust N Z J Ophthalmol. 1997;25(3):225-30, http://dx.doi. org/10.1111/j.1442-9071.1997.tb01397.x.

13. Hantson P, de Tourtchaninoff M, Simoens G, Mahieu P, Boschi A, Beguin $\mathrm{C}$, et al. Evoked potentials investigation of visual dysfunction after methanol poisoning. Crit Care Med. 1999;27(12):2707-15, http://dx.doi.org/10.1097/ 00003246-199912000-00018.

14. Essama Mbia JJ, Guérit JM, Haufroid V, Hantson P. Fomepizole therapy for reversal of visual impairment after methanol poisoning: A case documented by visual evoked potentials investigation. Am J Ophthalmol. 2002;134(6): 914-6, http://dx.doi.org/10.1016/S0002-9394(02)01798-1.
15. Brahmi N, Blel Y, Abidi N, Kouraichi N, Thabet H, Hedhili A, et al. Methanol poisoning in Tunisia: Report of 16 cases. Clin Toxicol (Phila). 2007;45(6):717-20, http://dx.doi. org $/ 10.1080 / 15563650701502600$.

16. Gupta N, Sonambekar AA, Daksh SK, Tomar L. A rare presentation of methanol toxicity. Ann Indian Acad Neurol. 2013;16(2):249-51, http://dx.doi.org/10.4103/0972-2327.112484.

17. Scrimgeour EM, Dethlefs RF, Kevau I. Delayed recovery of vision after blindness caused by methanol poisoning. Med J Aust. 1982;2(10):481-3.

18. Paasma R, Hovda KE, Jacobsen D. Methanol poisoning and long term sequelae - A 6 years follow-up after a large methanol outbreak. BMC Clin Pharmacol. 2009;9:5, http://dx.doi. org/10.1186/1472-6904-9-5.

19. Sadun A. Acquired mitochondrial impairment as a cause of optic nerve disease. Trans Am Ophthalmol Soc. 1998;96: 881-923.

20. Yu-Wai-Man P, Griffiths PG, Chinnery PF: Mitochondrial optic neuropathies - Disease mechanisms and therapeutic strategies. Prog Retin Eye Res. 2011;30(2):81-114, http:// dx.doi.org/10.1016/j.preteyeres.2010.11.002.

21. Carelli V, Rugolo M, Sgarbi G, Ghelli A, Zanna C, Baracca $\mathrm{A}$, et al. Bioenergetics shapes cellular death pathways in Leber's hereditary optic neuropathy: A model of mitochondrial neurodegeneration. Biochim Biophys Acta. 2004;1658 (1-2):172-9, http://dx.doi.org/10.1016/j.bbabio.2004.05.009.

22. Eells JT, Salzman MM, Lewandowski MF, Murray TG. Formate-induced alterations in retinal function in methanol-intoxicated rats. Toxicol Appl Pharmacol. 1996;140(1):58-69, http://dx.doi.org/10.1006/taap.1996.0197.

This work is available in Open Access model and licensed under a Creative Commons Attribution-NonCommercial 3.0 Poland License - http://creativecommons.org/ licenses/by-nc/3.0/pl/deed.en. 